\title{
MICROPHONE FRONT CAVITY DEPTH MEASUREMENT USING NON-CONTACT METHOD AT NATIONAL MEASUREMENT STANDARDS - NATIONAL STANDARDIZATION AGENCY OF INDONESIA
}

\author{
Pengukuran Kedalaman Rongga Depan Mikrofon Menggunakan Metode Tanpa Kontak \\ Di Standar Nasional Satuan Ukuran - Badan Standardisasi Nasional
}

\author{
Chery Chaen Putri dan Denny Hermawanto \\ Pusat Riset dan Pengembangan Sumber Daya Manusia, Badan Standardisasi Nasional \\ Gedung I BPPT Lantai 12, Jalan M.H. Thamrin No. 8, Jakarta, Indonesia \\ e-mail: chery@bsn.go.id
}

Diterima: 6 Februari 2019, Direvisi: 3 April 2019, Disetujui: 29 April 2019

\begin{abstract}
Front cavity depth of microphone has influence in the determination of laboratory standard microphone sensitivity. Therefore this parameter is included in the measurement uncertainty budget. To determine microphone sensitivity accurately, it is necessary to measure the actual front cavity depth instead of using nominal value. This paper explains the measurement of LS1P and LS2P standard microphone front cavity depth using optical depth measurement facilities at SNSU-BSN and its effect on determining microphone sensitivity. The measurement was obtained from 4 positions distributed over the diaphragm for each microphone. The front cavity depth measurement result for LS1P is $1,94 \mathrm{~mm} \pm 0,01 \mathrm{~mm}$ and for LS2P is $0,48 \mathrm{~mm} \pm 0,01 \mathrm{~mm}$ These results comply with IEC 61094 Measurement Microphones-Part 2: Primary Method for Pressure Calibration of Laboratory Standard Microphones by Reciprocity Technique as the results are within the permissible range.
\end{abstract}

Keywords: front cavity depth, microphone calibration, standard microphones

\begin{abstract}
Abstrak
Kedalaman rongga depan mikrofon memiliki pengaruh dalam penentuan sensitivitas mikrofon standar laboratorium. Oleh karena itu parameter ini termasuk dalam budget ketidakpastian pengukuran. Untuk menentukan sensitivitas mikrofon secara akurat, perlu dilakukan pengukuran kedalaman rongga depan yang sebenarnya daripada menggunakan nilai nominal. Makalah ini menjelaskan pengukuran kedalaman rongga depan mikrofon standar LS1P dan LS2P menggunakan fasilitas pengukuran kedalaman optik di SNSU-BSN dan pengaruhnya terhadap penentuan sensitivitas mikrofon. Hasil pengukuran diperoleh dari 4 posisi yang terdistribusi di permukaan diafragma mikrofon. Hasil pengukuran kedalaman rongga depan untuk LS1P adalah 1,94 $\mathrm{mm} \pm 0,01 \mathrm{~mm}$ dan untuk LS2P adalah 0,48 $\mathrm{mm} \pm$ 0,01 $\mathrm{mm}$. Hasil ini memenuhi persyaratan IEC 61094 Measurement Microphones-Part 2: Primary Method for Pressure Calibration of Laboratory Standard Microphones by Reciprocity Technique karena hasilnya berada dalam kisaran yang diizinkan.
\end{abstract}

Kata kunci: kedalaman rongga depan, kalibrasi mikrofon, mikrofon standar

\section{INTRODUCTION}

Sound level meters are calibrated by the substitution method (IEC 61672-3, 2013). The sound level meter will be placed in substitution of the microphone after the reference microphone measures the sound generated by the speaker. Meanwhile, sound calibrators are calibrated by insert voltage method as referred to IEC 60942 (IEC 60942, 2003). In this method, a voltage that equal with the voltage measured when sound calibrator generate sound pressure will be inserted through the reference microphone without passing the diaphragm. Through those methods above, the sound level meters and sound calibrators are traceable to the SI trough reference standard microphone. The magnitude sensitivity or pressure sensitivity level of a microphone is of primary importance to most microphone users, therefore it should be calibrated (Jacket \& Barham, 2013). Besides that, the standard microphone is also used to calibrate audiometer. An audiometer is a device used to diagnose and characterize the type of deafness and hearing loss. To avoid misdiagnose and to ensure reading accuracy, the audiometer must be calibrated. Therefore, to guarantee the microphone's measurement value, the microphone itself, should be calibrated.

The microphones used for reference are LS1P and LS2P which are calibrated by the 
reciprocity method as described in IEC 61094:2 (Nel, Van Zyl, \& Snyman, 2017). During the calibration, two standard microphones are coupled with each other, so that an air-filling cavity is formed between them (IEC 61094:2, 2000 \& Sang \& Jae, 2009). The air-filling cavity (coupling cavity) is associated with the acoustic transfer impedance which is a major component that has influence in sensitivity measurement (Victor \& Randall, 2008 \& Garg et al., 2018). Therefore, the values of microphone front cavity depths used in determining the acoustic transfer impedance must be determined before the microphone sensitivity can be computed (B\&K User Manual for Reciprocity Calibration Apparatus Type 9699, 1997).

Microphone front cavity depth must be measured by non-contact methods because its vulnerable diaphragm would be broken if measured by conventional contact method (Victor \& Randall, 2008). Until recently SNSU-BSN has used the nominal value of front cavity depth given by the manufacturer. However, it is suggested to measure the actual value of microphone front cavity depth because the use of its nominal value could lead to unacceptably large errors in determining the sensitivity of microphone at high frequency (Sang \& Jae, 2009 \& Victor \& Randall, 2008). As example, when two standard microphones are coupled and formed a tubular cavity with $\pm 0,1 \mathrm{~mm}$ error from the front cavity depths will cause an error of $\pm 0,7 \mathrm{~dB}$ in microphone sensitivity (Victor \& Randall, 2008). Thus to guarantee its measurement value, SNSUBSN performed an experiment in accordance with front cavity depth measurement. This paper explains the method of microphone front cavity depth measurement at SNSU-BSN by using depthfocusing microscope available in the dimensional laboratory and identified its effect to microphone sensitivity.

\section{BASIC THEORY}

A standard microphone has a lower section in the middle than at the edges known as the annulus. Front cavity depth is the difference in height between the diaphragm placed in the middle and the rim of the annulus. Figure 1 shows the physical form of the standard microphone.

In order to find the sensitivity of a microphone, two microphones with the same specifications are needed. The first one acts as a transmitter producing a sound signal, whereas the second one acts as a receiver. They are coupled with each other using the corresponding coupler as shown in Figure 2. The coupled microphones are then pressed at a certain pressure to produce a tight positive contact between the annulus and the coupler. In this setup work, a hollow space is formed between the two microphones, which is called the tubular cavity coupling. It is associated with the value of the microphone front cavity depths which is used in determining the acoustic transfer of the coupling cavity (IEC 61094:2, 2000). The correlation between microphone sensitivity and acoustic transfer impedance is shown in Equation 1. The latter depends on acoustic transfer volume which is correlated to the cavity volume created on the setup (Vorlander, 2013).

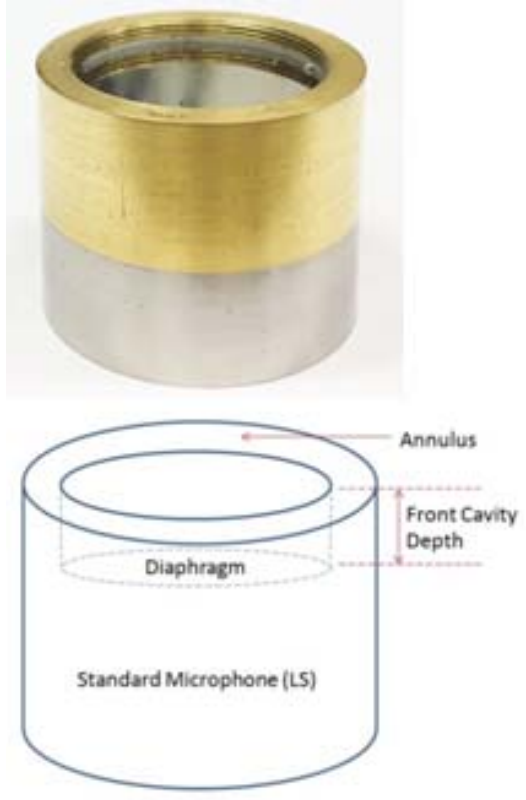

Figure 1 Laboratory standard microphone.

Equation 1 shows that microphone front cavity depth plays an important role in determining the sensitivity of a microphone. To get the correct microphone sensitivity, the value of the microphone front cavity depth must be measured.

$$
M_{p, x} \cdot M_{p, y}=\frac{1}{z_{a, x y}} \cdot \frac{u_{R, y}}{u_{C, x^{\prime} \cdot j \cdot \omega \cdot C}}=\frac{1}{z_{a, x y}} \cdot \frac{R_{x, y}}{j \cdot \omega \cdot C}
$$

Where :

$$
\begin{aligned}
& M_{p, x} \quad \text { : the sensitivity of microphone } \mathrm{x} \\
& M_{p, y} \quad \text { : the sensitivity of microphone } y \\
& u_{R, y} \text { : the output voltage of receiver } \\
& \text { microphone } y \\
& u_{c, x} \quad \text { : the voltage across the capacitor with } \\
& \text { microphone } x \text { as a transmitter } \\
& Z_{a, x y}: \text { the acoustic transfer impedance of } \\
& j \text { is } \sqrt{-1} \\
& \omega \quad: \text { the angular frequency } \\
& C \text { : the capacitance of the series } \\
& \text { capacitor }
\end{aligned}
$$




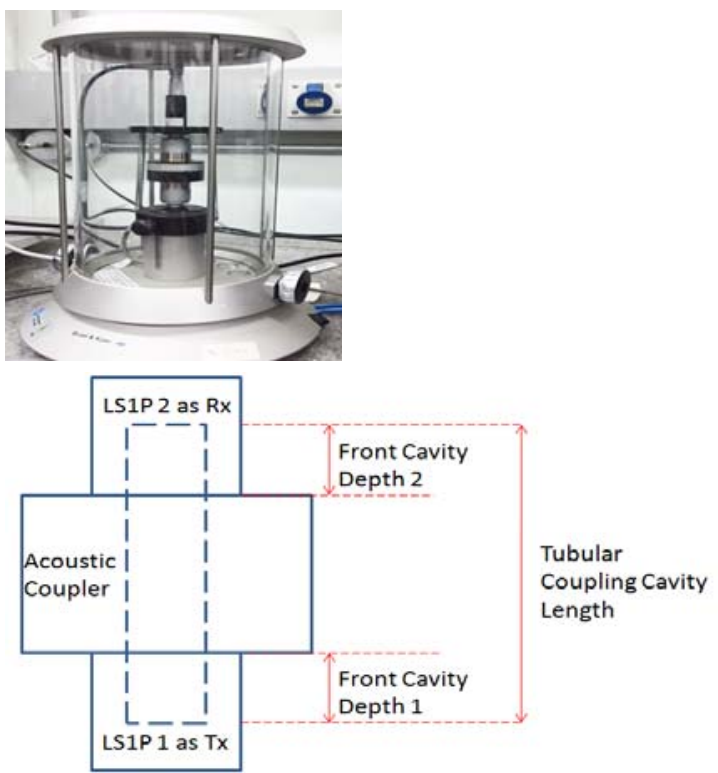

Figure 2 Microphone calibration setup.

Microphone front cavity depth is determined by the optical method. A contour plot across a diameter of the diaphragm and the outer rim that perpendicular to each other can be obtained by using an interferometric scanning technique by using a laser beam. Another method to determine the front cavity depth is by using a depth-focussing microscope. The measurement should be performed at some positions, distributed over the diaphragm and the top of the rim of the microphone (IEC 61094:2, 2000).

In a study carried out at NIST, Victor and Randall reported that two methods were applied to measure front cavity depth by using an optical depth-measuring microscope. Whilst the first method is a direct measurement at the microphone, the second one is an indirect measurement at the surface of a gage block placed on top of the microphone. Both were applied to six LS microphones and data were obtained at 33 and 25 measurement positions each for direct and indirect measurement subsequently. They also noted that the indirect measurement is preferable for several reasons. One of them is that it has smaller expanded uncertainty than the other method does. Microphone front cavity depth uncertainty by using indirect measurement was $4 \mu \mathrm{m}$ (Victor \& Randall, 2008).

At NPL, microphone front cavity depth was measured in Division of Mechanical and Optical Metrology (DMOM) using a depth-focusing microscope, at 4 points over the rim of the microphone and at 5 points over the diaphragm. The measurement was obtained from fifteen Type 4160 microphones, the averaged front cavity depth was $1,956 \mathrm{~mm}$ with the uncertainty of $0,003 \mathrm{~mm}$ (Delany \& Bazley, 1982).

\section{METHOD}

\section{A. Microphone Front Cavity Depth Measurement}

Microphone front cavity depth was measured by using a depth-focusing microscope and an analog dial indicator to monitor the displacement of the microscope. The microphone front cavity depth was calculated as the difference between the analog dial gauge readings at the surface of the microphone rim and at the surface of the diaphragm.

follows:

Equipment used can be described as

- Universal Measuring Machine, Societe Genevoise D'Instruments De Physique type SIP$414 \mathrm{M}$ (consists of micrometers and depthfocusing microscope)

- Dial Indicator, Mitutoyo type 0,001 mm

- Standard microphones, B\&K type 4160

- Standard microphones, B\&K type 4180

The Universal Measuring machine consists of a depth-focusing microscope with a magnification of 100 and a digital micrometer system. The digital micrometer was employed to read out the position along the $x$-axis and the $y$ axis with a resolution of $0,5 \mu \mathrm{m}$. An analog dial gauge was used for reading out the position along the z-axis. The set up for microphone front cavity depth measurement can be seen in Figure 3.

Front cavity depth measurement of two microphones LS1P and LS2P were performed at SNSU-BSN as part of the follow-up on acoustics laboratory assessment in 2015. Basically, front cavity depths were determined by placing the microphone under the microscope. Measurement positions at the diaphragm and the annulus were marked with numbers $1,2,3$, and 4 as shown in Figure 4. Front cavity depth measurement was performed on four points for each microphone with three measurements for each point. The measurements were repeated several times to ensure their precision and to determine the random uncertainty. The final front depth value is represented by averaging the measurement data set for each microphone type.

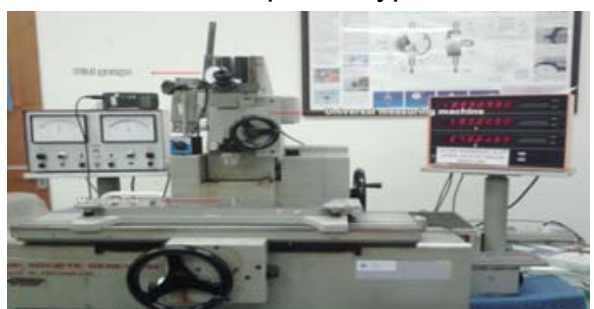

Figure 3 Front cavity depth measurement setup. 

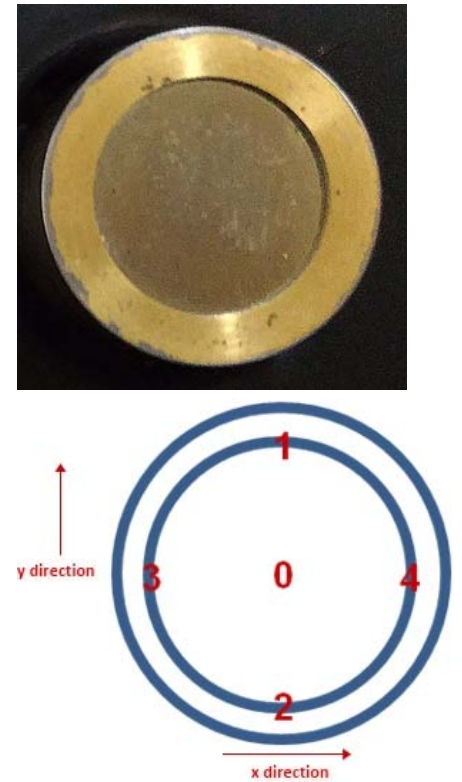

Figure 4 Front cavity depth measurement positions.

\section{B. Microphone Sensitivity Measurement}

The measurement of microphone sensitivity was performed by reciprocity calibration system in accordance with IEC 61094-2. Reciprocity calibration consists of measurements on three of the same type microphones followed by calculation procedure to calculate their sensitivity (Jae Gap, Wan Ho, Hack Yoon, Zhenglie, \& Yoiti, 2018). The microphones act as transmitter and receiver in turn. The sensitivity was determined in the whole range from $31.5 \mathrm{~Hz}$ to $25 \mathrm{kHz}$ in $1 / 3$ octave intervals.

Equipments used for measuring microphone sensitivity can be described as follows:

- Laboratory Standard Microphones, B\&K type 4160

- Preamplifiers, B\&K type 2673

- Reciprocity Calibration Apparatus, B\&K type 5998

- Pressurization Chamber, B\&K type UA1412

- Thermometer, Barometer \& Hygrometer, Vaisala type PTU 301

- PULSE Analyzer, B\&K type 3560C, based Reciprocity Measurement System with data acquisition software. The system consists of a Digital Voltmeter, a Band Pass Filter and a Signal Generator that are connected to a Personal Computer.

The measurement of microphone sensitivity was performed in a semi-automatic way. The microphone parameters (such as microphone front cavity depth, front cavity volume, equivalent diaphragm volume, resonance frequency, loss factor, etc.) (Rayburn, 2012) should be stored in a txt file to be used later by the measurement program. Two microphones are assembled acoustically by a coupler, one acts as a transmitter and the other as a receiver. A signal generator supplies the electric signal to the transmitter through amplifier contained in B\&K type 5998. The signal is then converted to an acoustic signal. The acoustic signal will cause the diaphragm of the receiver to moves back and forth because the changes in pressure or velocity. Further, the movement is converted to an electrical signal (Marshall, 2014 \& Ravaud, Lemarquand, \& Roussel, 2009) by electronic components of the microphone and finally is measured by digital voltmeter contained in PULSE analyzer. The ratio of the output voltage and the input current of the microphone is used to compute the microphone sensitivity. All the instruments and the measurements are controlled by computer and PULSE. The measurement setup can be seen in Figure 5.

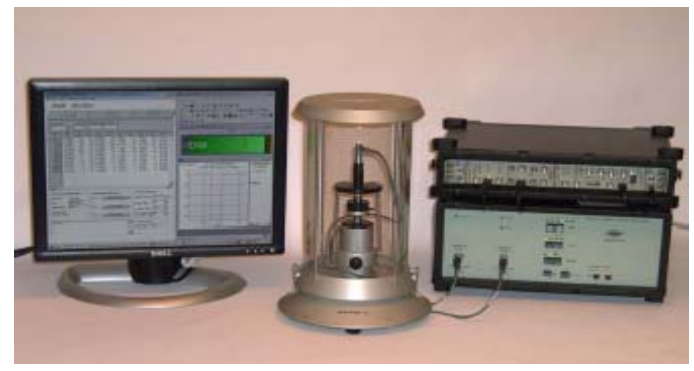

Figure 5 Reciprocity measurement system for microphone sensitivity measurement (courtesy of Brüel \& Kjær Sound \& Vibration Measurement).

\section{RESULT AND DISCUSSION}

The front depth measurement data for LS1P and LS2P are shown in Table 1. The table shows front depth measurement for position 1, 2, 3, and 4 . The measurement was taken 3 times for each point.

It can be seen from Table 1, that the measurement result is different for each position. For LS1P, front cavity depth for position 0-3 has smaller value than the other positions. Meanwhile, for LS2P, the second measurement shows a significant difference in front cavity depth measurement than the other measurements. Table 1 shows that position $0-1$ in the second measurement for LS2P has the highest value in front cavity depth measurement, which is $0,59 \mathrm{~mm}$.

From the experiment, it was found that microphone front depth value for LS1P serial number 2583067 and LS2P serial number 2564048 are $1,94 \mathrm{~mm} \pm 0,01 \mathrm{~mm}$ and $0,48 \mathrm{~mm} \pm$ $0,01 \mathrm{~mm}$. Compared to the microphone manufacturer's nominal value, the deviation is 0,01 $\mathrm{mm}$ for LS1P and $0,02 \mathrm{~mm}$ for LS2P. The final value for each microphone type does not exceed the permissible microphone front depth dimension as stated in part 1 of IEC $61094(1,95 \mathrm{~mm} \pm 0,1$ 
$\mathrm{mm}$ for LS1P and 0,5 $\mathrm{mm} \pm 0,05$ for LS2P). However, it was found in the experiment that there is a measurement result exceeds maximum value stated in IEC 61094 for LS2P.

Table 1 Front cavity depth measurement result for LS1P and LS2P.

\begin{tabular}{ccccccc}
\hline \multirow{2}{*}{ Position } & \multicolumn{3}{c}{ LS1P } & \multicolumn{3}{c}{ LS2P } \\
\cline { 2 - 7 } & $\mathbf{1}$ & $\mathbf{2}$ & $\mathbf{3}$ & $\mathbf{1}$ & $\mathbf{2}$ & $\mathbf{3}$ \\
\hline $\mathbf{0 - 1}$ & 1,96 & 1,96 & 1,95 & 0,50 & 0,59 & 0,48 \\
\hline $\mathbf{0 - 2}$ & 1,94 & 1,95 & 1,92 & 0,47 & 0,45 & 0,47 \\
\hline $\mathbf{0 - 3}$ & 1,92 & 1,93 & 1,94 & 0,46 & 0,45 & 0,46 \\
\hline $\mathbf{0 - 4}$ & 1,94 & 1,94 & 1,93 & 0,51 & 0,45 & 0,47 \\
\hline $\begin{array}{c}\text { Front } \\
\text { depth }\end{array}$ & $\mathbf{1 , 9 4}$ & $\mathbf{1 , 9 5}$ & $\mathbf{1 , 9 4}$ & $\mathbf{0 , 4 8}$ & $\mathbf{0 , 4 8}$ & $\mathbf{0 , 4 7}$ \\
$\begin{array}{c}\text { Average } \\
\text { (mm) }\end{array}$ & & & & & \\
\hline
\end{tabular}

The front depth value obtained in this experiment then used to find the microphone sensitivity. Figure 6 shows the microphone sensitivity resulted from this work. In this work, the microphone's sensitivity frequency range was measured from $20 \mathrm{~Hz}$ to $10 \mathrm{kHz}$ for LS1P and 20 $\mathrm{Hz}$ to $25 \mathrm{kHz}$ for LS2P. The measurement was taken by using computer operated automatic reciprocity calibration apparatus, B\&K 5998. In this work, three microphone sensitivity measurements were conducted. The first measurement was performed by using microphone front depth nominal value which is $1,94 \mathrm{~mm}$ for LS1P and 0,48 $\mathrm{mm}$ for LS2P. The second microphone sensitivity measurement was performed by using microphone front depth measurement value minus the measurement uncertainty which is $1,93 \mathrm{~mm}$ for LS1P and $0,47 \mathrm{~mm}$ for LS2P. And for the third measurement, microphone sensitivity measurement was performed by using front depth value plus the measurement uncertainty which is $1,95 \mathrm{~mm}$ for LS1P and 0,49 $\mathrm{mm}$ for LS2P.

The microphone sensitivity measurement result for 3 experiments (fd 0,47, fd 0,48, and fd 0,49 ) can be seen in Figure 6. The microphone sensitivity resulted from nominal front depth also shown in Figure 6 as comparison ( $\mathrm{fd} \mathrm{0,45} \mathrm{fd} \mathrm{0,5}$, and $\mathrm{fd} 0,55$ ). Figure 6 shows the relation between front depth (fd) and sensitivity in the way that smaller front depth value yields higher sensitivity. This is because smaller front depth will result in a bigger value in acoustic transfer volume. Whereas bigger acoustic transfer volume produces lower impedance in accordance with Equation 1. The 3rd measurement ( $\mathrm{fd} 0,49 \mathrm{~mm}$ ) shows lower negative $\mathrm{dBV}$ in sensitivity, which means that the microphone in the $3 \mathrm{rd}$ measurement is more sensitive than that in microphone 1st and 2nd measurement. Meanwhile the lowest negative dBV in sensitivity was exhibited by fd 0,45 from the nominal value which means the most sensitive. It occurred because smaller front depth will cause more acoustic transfer volume, which will result in smaller acoustic impedance, therefore, the sensitivity will be lower in - dBV sensitivity. However, most sensitive doesn't mean that it was the right value for the microphone, therefore to guarantee the microphone measurement value, it's better to use the microphone front depth that was obtained from the measurement result.

From the comparison of measurement result ( $\mathrm{fd} 0,47$, fd 0,48 , and $\mathrm{fd} 0,49$ ) and nominal value (fd $0,45 \mathrm{fd} 0,5$, and fd 0,55 ), it can be seen that the uncertainties produced from measurement experiments are much smaller than the uncertainties from the nominal value. A smaller uncertainty in front cavity depth leads to a smaller uncertainty component in microphone sensitivity calibration, especially at high frequency. For LS2P microphone, an error $\pm 0,10 \mathrm{~mm}$ in microphone front depth resulted in an error of $\pm 0,80 \mathrm{~dB}$ in microphone sensitivity at $25 \mathrm{kHz}$. By applying front depth value obtained from measurement using non-contact method, the error of the front cavity reduced to $\pm 0,02 \mathrm{~mm}$ which resulted in an error of only $\pm 0,17 \mathrm{~dB}$ in microphone sensitivity level.

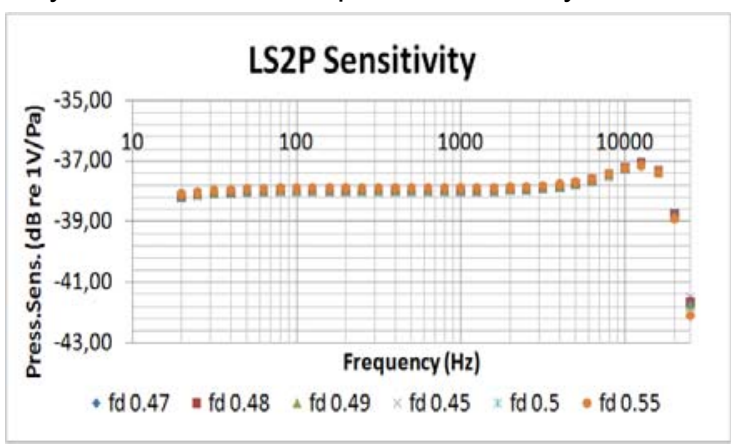

Figure 6 Microphone sensitivity.

\section{CONCLUSION}

The measurement of the microphone front cavity depth by the non-contact method has been conducted for both LS1P and LS2P microphones. This measurement result has confirmed that SNSU-BSN's microphone front cavity depths still complies with IEC 61094-2. It is also confirmed that front depth value has the contribution to the microphone sensitivity and therefore it is needed to be measured rather than using the nominal value given by the manufacturer. The front cavity measurement using non-contact methods produce uncertainties that are much smaller than that result from the use of the nominal value of front cavity depth. Furthermore, it is also needed to estimate other contributors of the uncertainty of this noncontact front depth measurement method for a 
formal procedure to be implemented in the laboratory.

\section{ACKNOWLEDGMENT}

We thank all the staffs of Acoustic and Vibration Laboratory and Length Laboratory for supporting and allowing us to perform the measurement on the Length laboratory. We gratefully acknowledge the support and generosity of Prof. Jimmy Pusaka for the guidance and feedback in writing this paper.

\section{REFERENCES}

B\&K User Manual for Reciprocity Calibration Apparatus Type 9699 (1997).

Delany, M. E., \& Bazley, E. N. (1982), Uncertainties in Realizing the Standard of Sound Pressure by the Closed Coupler Reciprocity Technique, Metrologia 18, 117132.

Garg, N et al. (2018), Reaffirmation of measurement uncertainty in pressure sensitivity determination of LS2P microphones by reciprocity method, Elsevier, Measurement 51, pp. 281-288.

IEC 61672-3 (2013). Electroacoustics-Sound Level Meters, Geneva, Switzerland.

IEC 60942 Ed.3 (2003), Electroacoustics-Sound Calibrator, Geneva, Switzerland.

IEC 61094 (2000), Measurement MicrophonesPart 2: Primary Method for Pressure Calibration of Laboratory Standard Microphones by Reciprocity Technique, Geneva, Switzerland.

Jacket, R. J. \& Barham, R. G. (2013), Phase sensitivity uncertainty in microphone pressure reciprocitycalibration. Metrologia 50. Pp. 170-179.

Jae Gap, S., Wan Ho, C., Hack Yoon, K., Zhenglie, C., \& Yoiti, S. (2018), Sensitivity measurement of a laboratory standard microphone by measuring the diaphragm vibration. Elsevier. Applied Acoustics 143.pp. 38-47.

Marshal, L. (2014), Acoustic Measurements and Noise Metrics. Academic Press. Architectural Acoustics-Second Edition. pp. 129-174. DOI 10.1016/B978-0-12-3982582.00004-0.

Nel, R., Van Zyl, B.G., \& Snyman, S.W. (2017), Analysing the effects of phase sensitivity in low frequency primary microphone calibrations. Elsevier. Applied Acoustics 127, pp 95-104.

Rayburn, A.R. (2012), Microphone Measurements, Standards, and Specifications. Focal Press. Eargle's The Microphone Book 3rd Edition: From Mono to Stereo to Surround - A Guide to Microphone Design and Application. Pp. 129-143. DOI 10.1016/B978-0-240-820750.00007-9.

Ravaud, R., Lemarquand, G., \& Roussel, T (2009), Experimental measurement of the nonlinearities of electrodynamic microphones. Elsevier.Applied coustics 70. Pp.1194-1195.

Sang Joon, S \& Jae Gap, S (2009). Final Report on the Bilateral Comparison of LS1P Microphone Calibration between KRISS and KIM-LIPI, APMP.AUV.A-K1.1, Metrologia 46, Tech. Suppl., 09003, pp. 1-84.

Victor, N \& Randall P.W. (2008), Non-Contact Methods for Measuring Front Cavity Depths of Laboratory Standard Microphones Using a Depth-Measuring Microscope, Journal of Research of the National Institute of Standards and Technology, Volume 113, Number 2, pp. 97-119.

Vorlander, M. (2013). Acoustic Measurement. In Muller G. \& M.Moser (Ed). Handbook of Engineering Acoustics (pp. 23-52), DOI 10.1007/978-3-540-69460-1_2. 